\title{
EDUCAÇÃO: DA FORM AÇÃO HUMANA À CONSTRUÇÃO DO SUJEITO ÉTICO
}

\author{
NeIDSON RODRIGUES ${ }^{*}$
}

RESU M 0 : Este texto elabora uma crítica e uma proposição em torno da questão educacional. A crítica denuncia a consensual concepção que atribui aos processos escolares atuai sos fins e meios de toda a E ducação. A centua quetal concepção articula a visão pragmática eutilitária predominante na ordem política e social do mundo moderno ao papel atribuído à educação escolar de preparar os educandos para o exercício da cidadania. Examina ainda - e recusa - a estreita relação que destina 0 atributo de cidadão aos indivíduos que se apossam dos conhecimentos e habilidades considerados necessários para que se integrem como força eficiente nos setores produtivos. 0 texto reconhece que 0 acesso a conhecimentos e habilidades constitui parte do processo de formação humana, mas não deve ser confundido com a totalidade do processo. E m seu aspecto proposicional, o texto põeem evidência a concepção de quea Educação éo processo integral deformação humana, poiscada ser humano ao nascer, necessita receber uma nova condição para poder existir no mundo da cultura. Esse processo inclui a aquisição de produtos quefazem parte da herança civilizatória eque concorreram para que os limites da natureza sejam transpostos. Entre eles se colocam os conhecimentos racionais que promoveram o desenvolvimento científico e cultural da humanidade, e a consciência de que o ser humano é 0 próprio produtor das condições de reprodução de sua vida edas formas sociais de sua organização e devem ser orientadas pelos princípios da solidariedade, do reconhecimento do valor das individualidades, respeito às diferenças, e pela disciplina das vontades. $\mathrm{O}$ Ser $\mathrm{H}$ umano, por não receber qualquer determinação por natureza, pode construir o seu modo de vida tendo por base a liberdade da vontade, a autonomia para organizar os modos de existência e a responsabilidade pela direção de suas ações essa característica do ser humano constitui o fundamento da formação do sujeito ético. Este deve ser o objetivo fundamental da Educação, ao qual devem ser submetidas toda e qualquer prática

* Prof. Dr. titular da Universidade Federal de Minas Gerais (UFMG). E-mail: neidson@educativa.org.br 
educativa, aí incluídas as escolares. Por último o texto discorre sobre 0 que 0 autor acredita ser o futuro da Escola. $\mathrm{N}$ a medida em quea ela vai se tornando o mais legítimo espaço na sociedade moderna para realizar a educação das crianças e dos adolescentes, ela terá de se tranforormar para recepcionar essa função que lhe caberá por injunção social: a de ser, não apenas, o lugar da escolarização, mas, sobretudo o da formação humana e o da formação do sujeito etico.

Palavras chave: Educação e formação humana; Educação e sujeito ético; Autonomia e educação; Educação e liberdade; Educação versus escolarização.

\section{Introdução}

Q ue horizonte pode ser demarcado para que o tema da Educação seja assediado na atualidade, sem que o texto se esvazie na repetição excessiva, ou em generalizações já esgotadas por discursos que reafirmam convicções para as quais não ocorrem imagens conceituais inovadoras? Eis uma das interrogações que inquieta nosso espírito.

Pode-se objetar que a questão educacional tem sido amplamente discutida e se tornado objeto de considerações as mais diversas, tanto do ponto de vista teórico, quanto das articulações práticas que mantém com a vida social. 0 tema tem sido abordado também no plano dos relacionamentos que arquiteta com as diversas formas de conhecimento, os processos produtivos, as inovações tecnológicas e a vida cultural. Podese mesmo sugerir, face a essas considerações, que não caberia outro esforço para escavar fundamentos velhos ou novos, pois ele não mais se apresenta virgem à inocência do entendimento.

Para nosso conforto intelectual, podemos verificar que a questão educacional alarga continuamente seu ponto de inflexão e o coloca para além dos anteriormente referidos e das interconexões que estabelecem entre si. N este texto, queremos acentuar a vinculação entre Educação e a ação formadora do ser humano, bem como o modo como essa vinculação se concretiza em diversas situações históricas. Esta perspectiva abre novas pistas que direcionam nosso espírito a um retorno original à natureza fundante da ação pedagógica: precisamos ir ao seu encalço.

Sabe-se que o contínuo movimento de recolher a mesma questão ou desconfiar do que foi, em algum momento, considerado conclusivo, permite ao investigador galgar um patamar mais elevado de resposta em relação ao momento anterior. 0 conhecimento só avança quando são colocadas, sob suspeita, conclusões já assumidas como verdadeiras. 
Por seu lado, se se admite que as questões referentes à E ducação se acham suficientemente esclarecidas, por certo que agora só caberiam interrogações de ordem prática, tais como: encontrar e estabelecer alternativas metodológicas e de políticas educacionais para uma dada sociedade, promover a adequação de conteúdos curriculares a uma concepção de realidade social e organizar formas de gestão para que os objetivos anunciados e aceitos sejam concretizados. No caso, a investigação poderia abandonar toda pretensão teórica e se situar no campo do que se define como prático e objetivo. A investigação se limitaria às considerações de natureza pragmática e utilitária.

Entretanto, nossa abordagem do tema pretende denunciar e romper esses limites em que o projeto social e cultural da educação tem sido aprisionado. E sair desse cerceamento nos leva a uma nova interrogação em torno do conceito essencial da Educação. E o que então propomos?

D e início, inverter as concepções do senso-comum a respeito dos fins da educação, pois creio ser necessário fazer um giro radical para trazer à luz os fundamentos da razão educativa. Para isso, começaremos por examinar se é aceitável, como anunciado com freqüência, que a justificativa mais fundamental para a ação educativa a situa na tarefa prática de preparar os indivíduos para a vida social. E ainda é necessário afirmar que se essa justificativa é recepcionada como premissa, pode-se então concluir que tanto o conceito de educação quanto os fins da ação educativa já são suficientemente conhecidos.

D e algum modo, essa é uma crença que tem sido assumida e reforçada em diversos discursos sobre educação. Q uase todos esses discursos põem em evidência o fim proclamado para a ação educativa como acima enunciado: "preparar os indivíduos para a vida social".

Ao definir os atributos do ato educativo como o de preparar os indivíduos para a vida social, institui-se um parâmetro universal sobre os fins da Educação. E esse parâmetro pode ser expresso em um outro discurso paralelo e a ele correspondente: 0 de formar os indivíduos para o exercício da Cidadania. 0 que se coloca como fim ou finalidade da ação educativa constitui-se, ipso facto, em seu próprio conceito. Um exame mais acurado dessas proposições indicaria que, por esse caminho conceitual, o discurso educativo acaba se convertendo numa proposição tautológica, e coopera para enfraquecer a construção de um bom entendimento a respeito do que seja a Educação.

Se as observações acima são pertinentes, podemos assegurar que 0 tema, recolocado como questão neste texto, circunscreve-se no esforço que 
cabe desempenhar para que seja construído um significado mais radical e rigoroso para a Educação e para o que se deve entender por cidadania.

\section{U ma hipótese ealguns corolários}

$\mathrm{N}$ a esteira do que foi reafirmado sobre os fins da educação, podemos reconhecer que a ação educativa é um processo regular desenvolvido em todas as sociedades humanas, que tem por objetivos preparar os indivíduos em crescimento (crianças e adolescentes) para assumirem papéis sociais relacionados à vida coletiva, à reprodução das condições de existência (trabalho), ao comportamento justo na vida pública e ao uso adequado e responsável de conhecimentos e habilidades disponíveis no tempo e nos espaços onde a vida dos indivíduos se realiza. Ao redor desses aspectos se desdobra o conjunto das ações educativas a serem desempenhadas pelos sujeitos educadores, entre eles a escola.

Essa concepção permite construir uma hipótese que se constituirá em objeto de análise a seguir. Essa hipótese se apresenta sob dupla face: uma positiva, por permitir compreender um processo histórico desde um tempo passado até os dias de hoje; e uma negativa, pois se sustentada do modo como se encontra formulada - e ela tem sido - inviabiliza ou pelo menos dificulta a construção de uma proposição mais radical sobre os conteúdos educacionais que devem ser pensados para o futuro. Essa hipótese pode ser anunciada da seguinte forma:

A aquisição de conhecimentoseasuautilização práticanaforma dehabilidades tornaram-se, ao longo dosúltimos dois séculos, nosfinsemeios para todas as atividades educacionaisnas sociedades modernase constituem em instrumentosfundamentais a serem possuídos por cada indivíduo na sociedade. 0 modo deaquisição ededistribuição desses conhecimentosehabilidadesseconstituiu em paradigma que organizatodos os processos educativos, eestabeleceo grau deresponsabilidadepara sua implementação por partedo poder público ou da iniciativa privada, nos planos individuaise coletivos, particulares euniversais. $\mathrm{N}$ o interior desse paradigma, as idéias de Educação ede Educação Escolar se fundem eestabelecem limites conceituais sobre os quaisse constróem os discursos reflexivos sobreos conteúdos daEducação, bem como sobreos objetivose os meios das políticas educacionais.

O ra, esta hipótese explicita o sentido que se atribui à Educação em geral e especialmente às práticas educativas desenvolvidas pela educação escolar. Aqui se articulam as relações práticas da educação e a sua necessidade à vida política e social, individual e coletiva. Ao redor dessas 
relações acredita-se que a Educação é o caminho necessário para a formação do sujeito-cidadão. Por decorrência, a questão da cidadania se torna uma questão a ser considerada com primazia.

\section{0 queéisto, a cidadania?}

No conjunto destas idéias, encontramos uma das proposições que oferece suporte para os grandes discursos a respeito do que se considera fim supremo da Educação escolar no mundo moderno: a preparação dos indivíduos "para o exercício da cidadania". Este fim, proclamado nas entrelinhas no denominado Relatório Condorcet, aprovado na Assembléia Francesa em 1792, se encontra reafirmado como princípio da Educação brasileira nos termos do artigo 205 da atual Constituição, no artigo 22 da Lei de Diretrizes e Bases da Educação $\mathrm{N}$ acional, e de modo semelhante ou aproximado em outros textos legais e normativos da Educação brasileira.

O vocábulo cidadania, no caso, recebe sua definição do conjunto semântico que a expressão "exercício da cidadania" carrega. 0 texto constitucional sugere que o conceito de cidadania resulta de uma função social - a prática da cidadania - onde o seu significado emerge. Similar a todo conteúdo semântico, ele só é plenamente compreendido na relação com a vida social. Por seu lado, é o ato concreto do exercício da cidadania que dá sentido ao termo cidadão. Portanto, cidadania é um atributo aplicado ao cidadão e, mais importante ainda: recebe sua legitimidade na ação educativa.

A educação cumpre esse papel ao dotar os educandos dos instrumentos que Ihes são necessários e pertinentes. Esses instrumentos são colocados em evidência ao serem descritos os meios educacionais que possibilitarão que todos os indivíduos cidadãos deles se apossem: organização e distribuição de conhecimentos e habilidades disponíveis num certo momento histórico, preparação para o trabalho, acesso ao desenvolvimento tecnológico, participação crítica na vida política.

Tais considerações, ainda hipotéticas no interior deste texto, levam-nos à necessidade de examinar, mais detidamente, o que se deve entender por cidadania, já que, para discutir o que se compreende por Educação, nosso raciocínio é conduzido para o labirinto conceitual que se ergue quando estabelecemos a relação entre esses dois termos: educação e cidadania. $\mathrm{N}$ ão será demais repetir que, em relação aos conceitos de cidadão e de cidadania, ainda estamos longe de um acordo consensual a respeito do seu conteúdo semântico. 
Um dos recursos metodológicos de que lançamos mão, com freqüência, ao procurar discernir os sentidos de um conceito, é procurar identificá-los em seu movimento histórico. N ão estou certo de que esse procedimento nos auxiliaria neste caso, pois esse caminho apenas ajudaria a conferir o modo como os conceitos de cidadão e de cidadania se movem no terreno das práticas relacionadas à vida política em qualquer organização social. Ser cidadão e exercer sua cidadania no mundo grego e romano era diferente de ser cidadão e exercer sua cidadania no Egito ou entre os hebreus. Ser cidadão no império czarista jamais foi o mesmo que ser cidadão nos estados americanos, a partir de sua independência, ou na Europa pós-revolução francesa. 0 mesmo ocorre nos tempos contemporâneos: o comportamento esperado do cidadão na antiga sociedade soviética não era o mesmo do outro lado da "cortina de ferro", ou da Alemanha antes e após a queda do muro de Berlin. E o que não dizer ainda dos sentidos diversos de cidadania nas sociedades liberais e neoliberais, e - desafio crescente hoje - no modo como se expressa ou se expressará a cidadania num mundo globalizado.

D esse modo, explicitar esse conceito torna necessário demonstrar a opção do modelo de sociedade, de organização social, de identidades históricas e de projetos de futuro em que ele é considerado. E ainda assumir que este conjunto de opções, racionais, fundadas em vontades e princípios, vai formatar o conceito de cidadão assumido e, por decorrência, explicitar o sentido dos termos "exercício de cidadania".

Para não estender por demasiado essa discussão, alguns dos contornos teóricos e práticos em torno dos quais são construídas as idéias de cidadão e de cidadania devem ser indicados. D o ponto de enraizamento histórico, remetemo-nos ao mundo clássico construído pelos gregos e que nos liga à idéia de pólis como comunidade constituída por indivíduos livres, autônomos, habitantes de um determinado espaço geográfico e social. Interessa-nos, sobretudo para este trabalho, considerar que para ser cidadão na Grécia clássica algumas condições deveriam ser preenchidas. Só poderia ser cidadão o indivíduo livre para expressar e exercer a sua vontade no espaço público e assumir as responsabilidades decorrentes dessa vontade. 0 cidadão tinha de admitir ter duas vidas: uma, a vida privada, e outra a Bíos Polytikós (a vida política) e é nesta que se faz a plena distinção entre o que é próprio de cada um e do que é próprio da vida coletiva. ${ }^{1}$

Tais características, exigidas para que a cidadania fosse reconheci$\mathrm{da}$, erguiam enormes entraves para diversos indivíduos e grupos sociais serem reconhecidos como cidadãos, tais como as mulheres, as crianças, 
os escravos, os estrangeiros e os habitantes pobres da pólis. N o entanto, o essencial do ponto de vista conceitual estava posto, tem valor permanente e universal, e constitui conteúdos válidos e universais: a cidadania se constrói nos fundamentos da liberdade, da autonomia e da responsabilidade. Estes conteúdos são condições para a cidadania, e fundamentos para a Ética. Eles constituem, por seu lado, a base sobre a qual serão erguidos os pilares da moderna sociedade de direitos no mundo ocidental. Será em torno de tais conteúdos que as idéias de democracia, de responsabilidade civil, de direitos individuais, de dever do poder público etc., serão construídas ao longo da história da civilização ocidental. ${ }^{2}$

Podemos dizer que a partir dos tempos clássicos, o conceito de cidadão se consolidou e incorporou outros grupos e indivíduos. Após a Revolução Francesa, estende-se progressivamente o reconhecimento de cidadania a um universo cada vez mais amplo da população, desde que preenchesse a condição constitutiva: a da liberdade e da autonomia.

Por isso, devem ser indicadas em que condições a liberdade e a autonomia - princípios constitutivos - se manifestam na cidadania. 0 cidadão é livre porque está certo de que sua vontade não será impedida de ser proclamada por injunções que Ihes são externas. Ele sabe que essa vontade implica responsabilidade e se articula às vontades de todos os outros cidadãos reunidos no mesmo espaço e tempo social. Seguindo esse rastro, a idéia de formação para a cidadania começa a ser dimensionada. Tendo em vista que as condições da cidadania são construídas, a Educação ganha papel central nesse processo.

0 exercício de cidadania compreende duas ações interdependentes: a primeira refere-se à participação lúcida dos indivíduos em todos os aspectos da organização e da condução da vida privada e coletiva; e a segunda, à capacidade que estes indivíduos adquirem para operar escoIhas. Ambos os aspectos caracterizam o sujeito identificável como cidadão. Como já apontamos que o exercício da cidadania pressupõe a liberdade, a autonomia e a responsabilidade, fica evidente que se constitui um dever dos cidadãos participar na organização da vida social. Essa organização deve assegurar a todos o exercício da liberdade e da responsabilidade.

Isso significa que a prática da cidadania deve demolir todas as interdições à construção de espaços de liberdade à ação dos cidadãos. Tais espaços são o locus onde o cidadão erige o seu modo de ser e de se expressar. Os cidadãos, munidos dos instrumentos da cidadania, tornam-se construtores de formas organizativas e de ação na vida pública. Essa forma de organização social e de ação política denomina-se D emocracia. 
Logo, a D emocracia é o modo como seres humanos autônomos, livres e responsáveis articulam as diversas vontades e capacidades individuais e coletivas para construir um modo de viver que lhes permita o mais alto grau possível de exercício de sua liberdade, em um espaço público. Este espaço público, na sua forma moderna de organização, pode se identificar com o Estado. A D emocracia é o projeto político mais completo e ambicioso dos tempos modernos. Se a prática da democracia não alcançou ainda uma relação perfeita de equilíbrio entre as vontades e as possibilidades dos indivíduos e dos grupos, ela é a única forma de organização política que encaminha os conflitos de vontades para processos de superação e de negociação independentes do recurso à violência. $M$ as, por ser projeto humano, está sempre aberto a novas possibilidades. A D emocracia não pode ser entendida como simples reestruturação de um regime político, ${ }^{3}$ nem ainda como organização mínima do poder constitutivo da organização social. Ela tem a ver como todo um conjunto de princípios ao redor dos quais se articula a totalidade da vida privada e pública dos cidadãos. A D emocracia é um projeto pleno de possibilidades.

E quando se diz que é um projeto, vem-nos à mente a condição concreta da democracia. Lançando mão de uma metáfora, podemos dizer que a democracia é semelhante a uma estrada que nos leva a um ponto que sempre se afasta quando dele nos aproximamos, e se 0 atingimos, ele não apresenta a aparência que nós Ihe atribuíamos. De certo modo, frustra-nos sempre. No entanto, é um projeto civilizatório que vem sendo construído, pedra sobre pedra, há mais de dois mil anos. Voltemos à nossa hipótese.

Ao retornar à hipótese enunciada, gostaria de extrair dela pelo menos três corolários a serem colocados em evidência. São os seguintes: I) devem ser tomados por cidadãos, ou estão aptos a exercerem a cidadania, todos aqueles que se encontram integrados à vida social; 2) para que essa integração ocorra, os indivíduos precisam ser portadores de habilidades para o exercício de uma função útil e reconhecida como legítima para si próprio, para sua família e para a comunidade. Por oposição chegamos a um terceiro corolário: 3 ) devem ser considerados não-cidadãos todos aqueles que se encontram afastados ou desalojados dessas condições básicas do exercício da cidadania. A esses são atribuídos os conceitos de marginais ou não integrados. Assim sendo, uma primeira conclusão pode ser deduzida da hipótese e de seus corolários: a Educação é o meio através do qual ocorre a preparação e a integração plena dos indivíduos para serem sujeitos na vida pública. 0 bserve 0 
leitor que com tal conclusão retornamos aos objetivos, meios e fins da educação, tais quais anunciados nos discursos sobre os quais fizemos referência na abertura deste trabalho. São, portanto, estes os aspectos os mais consensuais e que, por serem consensuais, não apresentariam dúvidas ao nosso espírito.

N o entanto, gostaria de examinar esses consensos e questionar essa conclusão, tendo em vista o dever intelectual de denunciar a dissonância de muitas idéias que se encontram tão arraigadas em nosso espírito que se convertem em um discurso ideológico. D e início, vamos questionar o próprio conceito de Educação contido da hipótese e reforçado pelo senso comum e a relação orgânica do mesmo com a cidadania, tal qual anunciada de modo consensual. Pretendemos para esse questionamento erguer outras bases de argumentação a partir das quais esse conceito ganhará outros contornos teóricos e práticos.

\section{0 que deveser isto, a Educação}

Kant nos fornece uma primeira aproximação conceitual para que sejam elaborados novos níveis de argumentos. D iz ele, em certo momento, que "o homem é a única criatura que precisa ser educada". ${ }^{4}$

Pois bem, esse enunciado nos convida a um diálogo com seu autor: por quê o homem é a única criatura que precisa ser educada? A proposição é uma assertiva sobre a educação e a sua relação com o ser humano é assumida como princípio fundante. Isto é: a Educação é necessária para que o Ser $\mathrm{H}$ omem seja constituído. $0 \mathrm{H}$ omem não se define como tal no próprio ato de seu nascimento, pois nasce apenas como criatura biológica que carece se transformar, se re-criar como Ser Humano. Esse ser deverá incorporar uma natureza em tudo distinta das outras criaturas. Ao nascer não se encontra equipado nem preparado para orientar-se no processo de sua própria existência.

0 ato de formar o ser humano se dá em dois planos distintos e complementares: um de fora para dentro e outro, de dentro para fora. Pelo primeiro, ele "precisa ser educado" por uma ação que Ihe é externa, de modo similar à ação dos escultores que tomam uma matéria informe qualquer, uma madeira, uma pedra, ou um pedaço de mármore, e criam a partir dela um outro ser. Assim como não se deve esperar que um objeto escultural apareça de modo espontâneo, também não se deve esperar que o ser humano seja fruto de um processo de auto-criação. É ainda K ant quem reafirma que "o homem não pode se tornar homem senão pela educação". ${ }^{5} \mathrm{~A}$ formação humana resulta de um ato intencio- 
nal, que transforma a criatura biológica em um novo ser, um ser de cultura. Esse ato denomina-se Educação. Em resumo: a Educação é um ato intencional imposto de fora sobre uma criatura que deve ser formada como ser humano. Sendo um ato intencional e externo, ele é desempenhado primeiramente pelos que antecedem na vida social os que estão sendo formados. N esse sentido, Kant igualmente assegura que a geração mais velha deveria educar a geração mais nova.

No entanto, o processo educativo não se reduz a essa formação externa. Ela é necessária, mas não suficiente. Se o fosse, 0 ato de educar seria um simples exercício de reproduzir o ser humano segundo um modelo externo, o que transformaria o ser humano num objeto a ser trabalhado por um sujeito formador. D ever-se-ia acreditar que há um modelo ideal ao qual devemos conformar os educandos. C reio ser esse 0 sentido atribuído à afirmação, muito difundida, de que educar é promover o ajustamento do educando a uma determinada realidade.

0 ra, educar não é somente isso. No segundo plano, educar compreende acionar os meios intelectuais de cada educando para que ele seja capaz de assumir o pleno uso de suas potencialidades físicas, intelectuais e morais para conduzir a continuidade de sua própria formação. Esta é uma das condições para que ele se construa como sujeito livre e independente daqueles que o estão gerando como ser humano. A Educação possibilita a cada indivíduo que adquira a capacidade de auto-conduzir 0 seu próprio processo formativo.

Esse roteiro coloca a questão educacional radicalmente distante da visão pragmática e utilitária a que foi direcionada nos tempos modernos. $N$ ão há dúvidas de que, desde a época em que Kant elaborou essa afirmação, novas demandas sociais e novos desafios políticos emergiram no tecido social. Estamos certos de que não se pode olvidar os conteúdos da declaração dos direitos do homem e do cidadão, as transformações na vida cotidiana, nas relações de poder e nas formas de trabalho introduzidas a partir da revolução industrial, o desenvolvimento das ciências e das técnicas e sua aplicação nos processos produtivos, a ameaça ao meioambiente, a organização dos Estados modernos, o advento da democracia burguesa, os movimentos ideológicos, as revoluções socialistas, a revolução dos meios de comunicação e de informação, o progresso da me dicina, o advento da sociedade em rede, a globalização.

No entanto, em que pese todo esse rebuliço na vida social, constata-se que há um aspecto permanente e fundante: tudo o que ocorre na vida social decorre da intervenção dos seres humanos. E este ser não emerge na vida à semelhança de Adão, pelas mãos e sopro divino, ou de 
Athena, de uma explosão da cabeça de Zeus. Pelo contrário. Ele emerge vagarosamente, pela ação formadora desenvolvida pelos adultos que vão re-formando essa criatura biológica até ela se tornar um ser humano.

Por analogia, podemos comparar esse processo ao crescimento das plantas. Após escolher o que se quer plantar, preparar o terreno e semear, deve-se cuidar de modo adequado para que a semente germine e se desenvolva na forma da planta. Se não houver ações externas à semente, como adubá-las e regá-las, elas tendem a não germinar. 0 esforço e a intervenção externa não garantem o nascimento e sua transformação em árvore. I sso só ocorre se a semente, devidamente adubada e regada, acionar mecanismos internos e próprios que fazem desabrochar os mecanismos que a levam a absorver a água da terra e 0 alimento que lhe são fornecidos para que cresça em força e vigor.

$\mathrm{N}$ ão fazemos a planta crescer, apenas fornecemos-lhe os meios para que cresça. $\mathrm{H}$ á de se cuidar dela a partir do nascimento, para que seja moldada às finalidades que lhe atribuímos. De modo semelhante ocorre na formação das crianças. Sabe-se que é mais fácil "semeá-las" do que formá-las. Após o seu nascimento e até a sua adolescência devemos lhes fornecer os meios - que são externos - para que desenvolvam sua capacidade intelectual, afetiva, psíquica, moral. Estes meios vão colaborar para seu crescimento e amadurecimento até o ponto em que a dependência em relação ao exterior seja eliminada ou reduzida ao mínimo possível. N esse momento, se poderá dizer que a criança percorreu os estágios da formação como ser social e alcançou sua maturidade e autonomia. O u dito de outro modo, chegou à sua maioridade.

0 ser nascente, não homem, ${ }^{6}$ necessita, pois, receber uma formação completa para poder existir junto aos outros homens como um ser igual e completo. N esse sentido, se diz da Educação que ela é uma totalidade, pois sua ação formativa abarca tanto a dimensão física quanto a intelectual, tanto o crescimento da competência de cada educando para se auto-governar quanto a formação moral que o leve a um adequado relacionamento com os outros homens.

Vamos inverter os termos e elaborar um outro tipo de questão para avançar em nosso diálogo com Kant. Por quê os animais não necessitam ser educados? E a resposta mais justa seria porque eles não necessitam acolher, de fora, nenhuma nova característica ou competência que já não Ihe é dada no próprio ato de nascimento, e adequada à sua espécie. $\mathrm{Os}$ animais nascentes não têm projeto de futuro, não se tranformarão em algo que já não são quando nascem. Q ualquer animal, no ato de seu nascimento, já está completamente formado e será idêntico à sua pró- 
pria espécie. U ma cobra, ainda na sua infância é o que será quando adulta. $\mathrm{N}$ ão irá adquirir habilidades, conhecimentos ou percepções diferentes do que a ela estão previamente destinados.

Com o ser humano isso é totalmente diferente. 0 ser que ele é, no ato de seu nascimento, será transformado para algo absolutamente diverso. Logo, o que é ao nascer, não-é, pois é apenas uma possibilidade, um projeto, uma intenção de futuro. A esse ser, que é apenas um devir, será oferecida uma possibilidade de vida, tanto do ponto de vista da sobrevivência quanto da realização de outras condições e possibilidades. I sso aponta para o fato de que o ser humano recebe uma educação que tem por fim produzir nele uma rejeição ao que Ihe é dado no nascimento, como natureza, para se tornar algo novo num mundo igualmente novo: uma vida inserida no mundo da cultura. E essa cultura nada apresenta de fixo e imutável, pelo contrário, é um eterno movimento em direção a algo que não se sabe o que pode ser.

Por isso, educar implica retirar do indivíduo tudo que o confina nos limites da $\mathrm{N}$ atureza e dar a ele uma outra conformação, só possível na vida social.

$N$ esse sentido, a Educação, entendida como o processo de formação humana, atua sobre os meios para a reprodução da vida - e essa é sua dimensão mais visível e prática - , bem como coopera para estender a aptidão do homem para olhar, perceber e compreender as coisas, para se reconhecer na percepção do outro, constituir sua própria identidade, distinguir as semelhanças e diferenças entre si e o mundo das coisas, entre si e outros sujeitos. A Educação envolve todo esse instrumental de formas de percepção do mundo, de comunicação e de intercomunicação, de auto conhecimento, e de conhecimento das necessidades humanas. E propõe-se a prover as formas de superação dessas necessidades, sejam elas materiais ou psíquicas, de superação ou de reconhecimento de limites, de expansão do prazer e outras. Educar requer o preparo eficiente dos educandos para que se capacitem, intelectual e materialmente, para acionar, julgar e usufruir esse complexo de experiências com o mundo da vida. Esta é uma responsabilidade a ser atribuída ao Educador.

\section{Q uem éo Educador e como ele atua}

M ontaigne nos lembra que "para exercitar a inteligência, tudo 0 que se oferece aos nossos olhos serve suficientemente de livro: a malícia de um pajem, a estupidez de alguém, uma conversa à mesa...".7 Curiosa 
observação, pois nos revela que o que se requer do educador é que promova nos educandos a sua capacidade de observação, de análise, de julgamento e de adesão. E para isso são igualmente úteis os preceitos e as teorias, a observação e a experiência cotidiana. D eve-se educar o espírito, mas também os olhos, ${ }^{8}$ isto é, os sentidos, pois o entendimento não cresce apenas com 0 alimento provido pelos conceitos, mas também com 0 que absorve ao interiorizar e processar intelectualmente 0 mundo observado e vivido. A educação deve, pois, formar o corpo e o espírito. Continua $M$ ontaigne, agora se dirigindo de modo especial ao educador: "quero que a delicadeza, a civilidade e as boas maneiras se modelem ao mesmo tempo que o espírito, pois não é uma alma somente que se educa, nem um corpo, é um homem: cabe não separar as duas parcelas do todo". ${ }^{9}$

Esse ser humano não herda as competências necessárias para vivenciar a diversidade das experiências nas quais estará inserido ao longo de sua vida. E como a sua vida não está delimitada pelo mundo natural, mas pela variedade do mundo cultural, carece de conhecer e dominar as formas do mundo cultural, admirável e complexo. Por isso é que há uma dependência estrutural da geração mais velha, aquela que recebeu anteriormente uma formação e que já viveu, antes da geração atual, um nível de experiência da vida social e que, por essa razão, deve se sentir melhor preparada para repassar saberes úteis a cada um que ainda vai iniciar sua jornada. Essa jornada não precisa começar do nada, mas do ponto em que todos se encontram aqui e agora.

Pode-se, desse modo, compreender que a Ação Educativa, enquanto Ação Formativa, é uma atividade extremamente complexa e de alta responsabilidade. Segue um percurso não espontâneo e casual e, em suas formas mais complexas e elevadas, deve ser conduzido por pessoas qualificadas para exercer a função de Educar.

$M$ as é bom que se atente para a consideração de que ela não pode ser de responsabilidade de nenhum indivíduo isoladamente, nem mesmo de qualquer instituição especializada. N enhum indivíduo isoladamente, por melhor preparo que tenha, será capaz de oferecer a outro a plenitude da formação de que ele necessita, bem como nenhuma instituição, ainda que seja definida como educativa, poderá dar conta desse papel. Essa tarefa é de responsabilidade social. Pode ser que a sociedade não realize a melhor educação que se deseja, mas ela realizará a melhor educação possível.

Ao dizer que os mais velhos devem educar os mais jovens, indicamos um pressuposto como parte do enunciado. Q ual é esse pressupos- 
to? Podemos destacá-lo da seguinte forma: no processo educativo há uma experiência a ser transmitida aos mais jovens e ela só pode ser bem conduzida por parte de quantos a tenham vivido e que a compreendam como necessária na construção do mundo humano. Podemos questionar: como se dá esse processo de troca de experiências, quando, em que circunstância ele tem início e quais são seus conteúdos fundamentais?

5. Primeiro conteúdo do processo formativo: a construção da linguagem ou do mundo simbólico

Vamos tratar, em primeiro lugar, do mais original dos meios de produção do mundo humano: a linguagem. Talvez seja este o único produto humano que pode ser considerado fim e meio sob a mesma relação. Sem a linguagem não há o mundo cultural e por ela esse mundo é construído. São diversas as referências que poderiam reforçar o grau de consciência da importância fundamental da linguagem na história da cultura. Entretanto, vamos utilizar a ponderação a seguir a respeito da linguagem, que creio ser suficientemente representativa para a discussão pretendida. ${ }^{10}$

Gadamer ${ }^{11}$ afirma que "a linguagem não é somente um dos dotes, de que se encontra apetrechado o homem, tal como está no mundo", mas que ela representa o fato de que o homem "simplesmente tem mundo". O mundo está aí para os homens de uma forma absolutamente diferente do modo como está para qualquer outro ser vivo. Ela estabelece não apenas o modo de apreender e dominar o mundo, mas o modo humano de ser no mundo, pois é por ela que o homem se coloca como ser autônomo frente ao mundo. Pela linguagem Ihe é assegurada a plena posse da liberdade.

Continua Gadamer: "Ter mundo quer dizer comportar-se para com o mundo. M as comportar-se para com o mundo exige, por sua vez, que nos mantenhamos tão livres, face ao que nos vem ao encontro a partir do mundo, que consigamos pô-lo ante nós tal como é". Ter mundo é ser capaz de construi-lo e de possui-lo pela linguagem. O ra, isso muda o próprio conceito de "mundo circundante", pois o conceito de mundo para o homem se apresenta em oposição ao conceito de mundo circundante para qualquer outro ser vivo que está no mundo.

Por mundo circundante não se deve entender apenas o meio físico em que o homem vive. Claro que o homem não é independente desse meio. Esse meio o toca e o influencia. M as há um detalhe só possível ao 
homem: enquanto os animais vivem no mundo, ou estão a ele confiados, o homem tem mundo, isto é, o mundo lhe pertence como fruto de sua produção. Esse mundo, por ser produzido pelo homem, é feito à sua imagem e semelhança. Corresponde tanto ao modo como o homem se relaciona com o mundo físico, com o meio-ambiente, quanto com o modo como se relaciona consigo mesmo, com os outros homens e com o produto civilizatório por ele instituído. Aqui se entrelaçam temas relativos à vida cultural, social, política, e de responsabilidade ética, individual e coletiva desse ser humano.

O ser humano é um ser livre em relação ao mundo circundante, na medida em que o mundo é produto de sua linguagem. $\mathrm{H}$ omem e mundo são partes de uma mesma relação. A multiplicidade de linguagens não advém, como quer o mito da Torre de Babel, de uma confusão de línguas a partir de uma língua originária. $\mathrm{N}$ a realidade é 0 contrário, pois "as coisas se explicam de outro modo: porque o homem está capacitado a elevar-se sempre acima de seu mundo circundante casual, e porque seu falar traz o mundo à fala, está dada, desde o princípio, sua liberdade para um exercício variado de sua capacidade lingüística". ${ }^{12} \mathrm{E}$ poderíamos acrescentar: sua liberdade para reproduzir 0 mundo da cultura.

A que as considerações acima nos remetem? Em que se relacionam com o processo de formação humana, do qual estamos tratando? Bem, elas tocam em pelo menos três aspectos que cobrem o processo formativo da ação educacional. Vamos considerá-los em seguida. 0 primeiro refere-se à construção simbólica da realidade, isto é, a aquisição da linguagem, sem a qual não há mundo humano. 0 segundo refere-se à disciplinação da vontade e à aquisição de conhecimentos e habilidades de que cada um irá se servir para atuar na reprodução das condições próprias de existência e de participação enquanto membro da sociedade. $\mathrm{N}$ ão se pode ignorar que esse processo só se torna possível porque o indivíduo já se encontra inserido no mundo humano que é o mundo simbólico. 0 terceiro aspecto coroa todo o processo educativo e sua duração se estende por toda a vida dos sujeitos: trata-se da formação do sujeito Ético. Este só pode ocorrer pela aquisição do mais alto grau de consciência de responsabilidade social de cada ser humano, e se expressa na participação, na cooperação, na solidariedade e no respeito às individualidades e à diversidade. Em que pese 0 fato de não podermos tratar de todos estes aspectos exaustivamente, vamos considerar alguns dos que evidenciam as razões pelas quais eles não podem ser ignorados. 
Comecemos pela construção simbólica da realidade. D esde o início, os adultos tendem a fazer com que as crianças modifiquem as formas de expressão de suas vivências naturais, como aquelas que expressam fome, sede, insegurança, necessidades fisiológicas e as diversas afecções produzidas pela experiência sensitiva com as coisas que as cercam, como a luz, o calor, o frio, a dor. 0 riginalmente, a expressão dessas experiências é de natureza reativa e se manifesta materialmente na forma de choro, riso, gritos, paralisia. 0 que desejam os adultos? Q ue as crianças transformem esses gestos reativos em um gesto simbólico inteligível ao adulto. Somente essa inteligibilidade construirá uma ponte para que ambos, crianças e os que as cercam, organizem uma relação comum da experiência que está sendo vivenciada. Atendida essa condição, poderá haver uma troca de experiências e os adultos poderão estimular as que produzem satisfação e evitar ou minorar as que difundem desconforto ou aborrecimento.

Antes mesmo de serem capazes de expressar sua experiência de modo simbólico, as crianças são levadas a perceber que os seres humanos adultos são incapazes de entender a expressão de suas reações naturais com as coisas, pois ao longo da vida social foi sendo gestada uma ruptura radical entre os adultos e a natureza. Por isso, todos se empenham para que nelas aflore a expressão simbólica do mundo, pela qual devem exprimir as suas experiências elementares e naturais. D esde cedo, re quer-se que as crianças sejam capazes de falar, pois a fala organiza as condições para uma intercomunicação com os adultos. 0 mundo, traduzido simbolicamente, emerge no plano da consciência dos indivíduos em tudo diferente da natureza, pois é o próprio mundo cultural.

$M$ as poder traduzir simbolicamente 0 mundo não é suficiente. $A$ partir desse momento, começam a germinar formas novas de expressão da sensibilidade e de produção de sensibilidades. 0 ser humano deve não apenas sentir o mundo, mas estabelecer correlações, valores, antever experiências, avaliar, fixar, repetir ou evitar o que se considera positivo ou negativo (bom e mau, bonito, feio, agradável, desagradável), enfim, desenvolver as potencialidades da sensibilidade e da memória.

Espera-se que o ser humano seja capaz de conhecer o mundo que Ihe antecipa na ordem da existência e reconhecer que o existente é composto de um conjunto de coisas que não depende dele para existir. Há também um conjunto de coisas que poderiam não existir, que poderiam ser diferentes do que são, que podem ser incorporadas à minha existência ou não, e de outras que guardam interesses diversos para pessoas diferenciadas. 0 mundo humano é esse mundo diferenciado, construído 
simbolicamente e que, quanto mais complexo, mais denuncia a distância entre o mundo humano e toda a chamada realidade primeira.

Para viver esse mundo cada um deve ser preparado para se relacionar com o existente, adaptar-se ou a ele se adequar na qualidade de herdeiro dos produtos das gerações que o precederam. Como esse ser é dotado de vontade infinita, mas de possibilidade finita, há de disciplinar essa vontade para que ela possa ser ajustada à realidade em que se está colocado. D e al gum modo, o mundo já existia antes dele, recepcionao e o convida a ser participante de sua reconstrução. Além de herdeiros, os novos sujeitos humanos precisam desenvolver meios próprios para participarem na conservação e na transformação do mundo humano.

Estas observações nos indicam que já estamos a tangenciar o plano dos conhecimentos e das habilidades indispensáveis a todos, e que são desenvolvidos de modo diferenciado por e em cada um. $\mathrm{N}$ inguém necessita, nem terá competência para conhecer tudo o que o ser humano produz e como o produz, nem possuirá todas as habilidades disponíveis no mundo humano. D emarcar esse grau de consciência permite que os seres humanos adquiram capacidade seletiva e noção de limites que só podem ser estendidas nos meandros da intercomunicação cooperativa com outros homens. 0 s seres humanos descobrem que não estão sós no mundo, nem realizam a sua existência de modo solitário e isolado. Ele necessita construir inter-relações com outros seres humanos e com a natureza.

I sso nos leva a um terceiro plano. Relembremos: o primeiro é o do reconhecimento do mundo e de sua transformação em mundo simbólico. 0 segundo inclui a disciplinação da vontade e a aquisição dos conhecimentos e das habilidades que constituem a herança social que cada um recebe ao ser transformado em sujeito cultural. E o terceiro deve levar cada um ao reconhecimento de que não é capaz de traçar seu próprio destino sem o concurso das relações instituídas no mundo humano. 0 ser humano deverá ser formado para a ação cooperativa, para a solidariedade, para a aceitação do outro, para a noção de limites e para construir a noção de dever. N este plano, estamos ingressando no que se deve entender como o da formação e desenvolvimento dos princípios da Ética e da M oral, necessários a todos os homens. Somente neste plano pode-se considerar completa a tarefa do que se diz por Educação.

Educar integralmente quer dizer, pois, formar o ser humano nos três planos assinalados. Aí se colocam os patamares de toda educação necessária e completa. $\mathrm{H}$ á de se inserir o homem no mundo social e 
disciplinar os seus impulsos naturais; desenvolver nele a capacidade do entendimento e do conhecimento; organizar e promover habilidades necessárias à produção e re-produção das condições próprias de existência; prepará-lo para compreender-se como partícipe de um processo civilizatório, no qual se torna responsável com o bem estar pessoal e dos outros, e com a incessante busca da felicidade.

Enfim, podemos agora perguntar: em que momento se pode dizer que a Educação cumpriu integralmente sua tarefa? Como identificar o homem formado como sujeito ético?

\section{0 segundo conteúdo do processo formativo: a formação do sujeito deautonomia e deliberdade}

O H omem educado é aquele que atingiu a sua maioridade, que se emancipou de todos os que foram os condutores dos seus primeiros passos. ${ }^{13}$ Ao se emancipar, torna-se 0 condutor do próprio processo de reformação, de auto-desenvolvimento.

Consideremos, a título de exemplo, 0 ato de ensinar alguém a ler e escrever. Essa ação se desdobra a partir de procedimentos considerados impositivos e externos ao aprendiz. Q uem ensina determina os passos a serem seguidos por quem aprende, desde o reconhecimento de símbolos gráficos até a identificação de palavras, frases e de sua significação. D o mesmo modo Ihe são determinados os movimentos mecânicos, tais como o modo de segurar o lápis ou a caneta, o ritmo e a direção a ser seguida no ato da escrita. 0 que, no entanto, se coloca como alvo para 0 aprendiz? Por certo que ele adquira independência em relação ao seu pedagogo. Espera-se que, após um certo nível de aprendizado, ele escreva o que deseja escrever e leia o texto de sua escolha. Ao se tornar competente para operar tais escolhas, ele adquiriu autonomia, libertou-se de quem Ihe orientou os primeiros passos. Essa é a diretriz básica da educação: educa-se para a emancipação, para a autonomia.

E que aspectos podem ser destacados para que seja reconhecida a situação de autonomia nos sujeitos? Podemos indicar que, pelo menos três: 0 da autonomia da vontade, o da autonomia física e o da autonomia intelectual. 0 sujeito se torna autônomo, no primeiro plano, quando capaz de estabelecer relações de equilíbrio racional entre suas emoções e paixões. I gualmente, ao se tornar capaz para assumir a responsabilidade pelo próprio corpo e as relações equilibradas com o mundo natural. E, acima de tudo, quando determinar e escolher livremente os meios e os 
objetivos de seu crescimento intelectual e as formas de inserção no mundo social. Preenchidas essas condições, ele pode ser reconhecido como sujeito social.

Poderíamos demonstrar, por exemplo, algumas situações que auxiliam a compreensão dos aspectos acima colocados. $\mathrm{N}$ o caso do equilíbrio entre emoções, paixões e disciplina da vontade, é bastante inteligível o comportamento infantil e como ele se diferencia do adulto. As crianças, geralmente, não têm paciência para esperar que sua vontade seja atendida nas mínimas coisas, e na adolescência ocorre a tendência para se imaginar que toda e qualquer vontade poderá ser realizada. Isto torna o comportamento dos adolescentes incômodo aos adultos. Q uase sempre eles expressam de modo irritado a sua insatisfação diante de qualquer interdição a seus desejos e querem alcançar seus objetivos ainda que com o uso da força. Têm dificuldade para negociar, adiar ou alterar a sua inclinação inicial.

O ra, tais comportamentos, quando permanecem na fase adulta dos indivíduos, denunciam que estes indivíduos não ultrapassaram a sua fase infantil ou adolescente, isto é, não atingiram sua maioridade. Comportam-se como crianças ou adolescentes porque não desenvolveram uma das condições da autonomia: disciplinar a vontade e articular paixões, necessidades e racionalidade.

N o outro plano, o da autonomia física, ocorrem situações semeIhantes. Ao nascer, todos desconhecemos o funcionamento próprio do corpo e, por issso, agimos por reação e segundo os limites e movimentos naturais. É assim que qualquer criança é capaz de se alimentar, ingerir líquidos, expelir excrementos e manifestar desconforto como dor, frio, medo. Não sabe, de início, cuidar do corpo físico e desconhece as necessidades ligadas à higiene, ao descanso, ao manuseio das mãos, e mesmo das potencialidades escondidas na mente e nos sentidos. 0 ra, a educação deve abrir tais possibilidades aos indivíduos. Inicialmente, orientamos as crianças a evitar o perigo, a executar atos de higiene, a se alimentar adequadamente, enfim, insistimos no desenvolvimento de hábitos considerados sadios e moderados. 0 que esperamos? Certamente que as crianças, na medida em que vão se tornando adultas, adquiram autonomia. E quando a terão adquirido? A partir do momento em que puderem dirigir o seu próprio corpo para uma relação saudável consigo mesmo e com o mundo natural. I sto vai levá-la a tomar decisões sobre a própria higiene, alimentação, descanso, preservação da natureza e de relações sociais, operar escolhas em relação ao uso do corpo etc. 
E, por último, a autonomia intelectual. Esta é a mais fundamental e complexa, porque é ponto de partida e ponto de retorno de todo 0 processo de desenvolvimento dos fundamentos da autonomia, aí incluídos os da autonomia física e da vontade. 0 modo como o ser humano se relaciona com o mundo, já o dissemos, tem um ponto de inflexão sobre o qual tudo o mais é construído: a transformação da experiência sensível em experiência simbólica. Por certo tiveram os gregos sobejas justificativas para usarem um mesmo vocábulo - Lógos - para expressar duas idéias distintas, mas profundamente articuladas: a racionalidade e a expressão discursiva do mundo, enfim, Razão e Linguagem. 0 ser humano, produto da racionalidade, desenvolve as diversas formas de linguagens com o que incorpora e produz o mundo natural e cultural, bem como cria meios e fins para disciplinar e para organizar seu modo de existir. Esses meios e fins são identificados nas regras da vida social, nas formas institucionais criadas para agregar e promover a vida social nos projetos de futuro que desenha para si e para a humanidade. Encontramos estes produtos nas instituições religiosas, na família, no Estado, nas leis, nas regras morais, nas instituições punitivas, nas empresas, nas instituições científicas e tecnológicas, nas organizações internacionais e corporativas.

0 sujeito social autônomo é aquele que circula e atua no conjunto da vida social de forma independente e participativa. Para isso, requer-se que ele também seja capaz de estabelecer juízos de valor e assumir responsabilidades pelas escolhas. 0 fundamento ético da humanidade se assenta no tripé constituído pelo reconhecimento de si mesmo como sujeito (individualidade), na liberdade e na autonomia. A consciência deste tripé se frutifica pela ação educativa, que constrói no ser humano a capacidade para incorporar estes valores.

$\mathrm{N}$ ão se pode desconhecer, no entanto, as enormes dificuldades para que o ser humano atue na vida social norteado por essa regulação. 0 mundo humano não é um mundo pré-determinado. Não sendo prédeterminado, ele é um produto que resulta da confluência de fatores diversos como os da vontade, da autonomia dos sujeitos, e de como se articulam os projetos que ultrapassam os limites individuais. Tudo isso ainda precisa ser combinado com um quadro de valores que orienta as escolhas de cada um e que pode se alterar em função dos mais diversos fatores, como os conjunturais, os dos espaços sociais em que os indivíduos vivem, as relações de gênero, as expectativas sociais dos indivíduos ou de grupos com os quais os indivíduos se relacionam, os círculos de amizade e até mesmo os estados emocionais. 
Isto significa que nem mesmo os valores, como os da justiça, da eqüidade e da liberdade, as crenças e os projetos, as concepções de Estado e de organização política, são passíveis de entendimento e de adesão uniformes por parte de todos os cidadãos. A consciência de liberdade, de igualdade, de participação e de disciplina da vontade, ao atingir o patamar da maturidade nos indivíduos, deve orientar os seres humanoscidadãos a compreenderem a importância de outros princípios e valores, sem os quais a vida social se destruirá, entre eles: a tolerância, a cooperação, a solidariedade, a humildade, o respeito, a justiça. Eis alguns dos grandes desafios para a ação educativa como ação formadora do ser humano.

Podemos observar como se torna insuficiente a formulação mais tradicional da Educação que se confina na visão de escolarização, e esta na aquisição de conhecimentos e habilidades. O ra, gostaria de utilizar uma sugestiva afirmação de Isaiah Berlin, em Limites da utopia. Diz ele que não há nenhuma grande tragédia na história da humanidade que não tenha sido implementada em nome de um princípio considerado verdadeiro. E gostaria de continuar dizendo que todas as grandes tragé dias que a humanidade conheceu resultou de ações implementadas por indivíduos ou grupos humanos dotados dos conhecimentos e dos recursos tecnológicos mais avançados à época dessas tragédias. D esse modo, podemos desconfiar de que o domínio de conhecimentos e de habilidades não garante 0 desenvolvimento humanitário nos educandos, porque não promove, por si mesmo, a formação ética do ser humano. Essa formação ética é uma necessidade do processo formativo humano, que não pode ser reduzida a uma simples tarefa de produção, organização e distribuição de conhecimentos e de habilidades. A formação humana só estará completa se acompanhada do desenvolvimento de princípios de conduta que possam ser reconhecidos como de validade universal.

Para concluir, gostaria de traçar algumas considerações em torno do Educador, necessário para construir esse futuro, tendo por fundamento 0 presente.

\section{C onclusão: al gum olhar para o futuro desde o presente}

Q uem é o educador-formador desse sujeito humano? Tradicionalmente, essa é tarefa inicial da família, a começar dos pais, passando a outros membros e a todos os adultos que convivem, desde o início, com as crianças. Em segundo lugar, já foi um papel desempenhado pelas comunidades, pois constituíam um corpo educativo formado, princi- 
palmente, pelos mais idosos, que preservavam os princípios a serem seguidos por todos os membros da vida comunitária. A religião também já desempenhou um poder educativo em relação a uma série de valores invocados pelas comunidades. E, por último, as instituições sociais, como o Estado e seus aparelhos, a justiça, os partidos políticos, as organizações da sociedade civil e, do ponto de vista dos conhecimentos e habilidades, as instituições educacionais.

O ra, o que ocorre nos últimos tempos? Assiste-se a uma desintegração dessas unidades educativas. As famílias têm perdido sua hegemonia educativa, na medida em que desestruturam as relações tradicionais entre seus membros. E não estamos a nos referir apenas às famílias das classes pobres, mas de todas as chamadas unidades familiares. Os pais estão cada vez mais ausentes da vida dos filhos, desde os primeiros dias de suas vidas. I gualmente, a I greja deixou de representar uma instituição unitária e hegemônica, capaz de dar direção moral às novas gerações. $\mathrm{E}$ as comunidades desapareceram nas formas novas de organização da vida coletiva nos tempos modernos. Cada vez mais as pessoas apenas vivem fisicamente próximas, sem qualquer unidade de projetos sociais, de princípios éticos, de trabalho, de dever, de relações. As cidades, por sua vez, se transformaram em simples aglomerações populacionais e não são formas de organização humanitária da vida coletiva.

Como conseqüência, há enormes perdas de meios educativos na vida contemporânea. A única instituição que ainda mantém uma presença universal é a instituição escolar. Curiosamente, é ainda a única instituição para a qual se dirigem e são dirigidas todas as novas gerações, desde seu nascimento.

Assim, gostaria de proclamar a seguinte perspectiva, que pode ser considerada como crença ou aposta de futuro: cada vez mais a Escola exercerá ou poderá exercer um papel que a ela jamais foi atribuído em tempos passados: 0 de ser a instituição formadora dos seres humanos.

0 processo educativo que ela deverá desenvolver não poderá ser fragmentado e hierarquizado, nem qualquer de suas partes ser eleita como mais importante do que outra. Esse procedimento tenderia a uma espécie de ideologização da Educação. M as isso tem acontecido. Em que sentido?

D esde os primórdios dos tempos modernos que al guns dos procedimentos próprios da ação escolar, isto é, a transmissão, a aquisição e o desenvolvimento de conhecimentos e habilidades têm sido destacados e constituídos em núcleo central da Educação. 0 s processos de escolarização têm colonizado a Educação. 
Pode-se identificar a lógica desse fenômeno. A partir dos tempos modernos ocorreram diversos movimentos para universalizar a Educação Escolar e essa universalização tem sido cada vez mais entendida como universalização da Educação. Como a Educação Escolar sempre teve por característica central lidar com questões do conhecimento e da formação de habilidades, ambas as concepções de Educação Escolar e Educação foram se identificando até dissolver absolutamente o sentido de formação humana. A concepção de formação foi reduzida ao plano dos domínios dos conhecimentos.

$\mathrm{N}$ o entanto, pode-se perceber, na atualidade, um movimento crescente em sentido contrário. $\mathrm{N}$ a medida em que os meios e as formas tradicionais de Educação acham-se de tal modo corroídos, começam a ser direcionados para a Escola os olhares dos povos, na esperança de que esta exerça uma função Educativa e não apenas a da Escolarização. Somente que será necessária uma outra visão da Escola, dos conteúdos escolares, do papel dos educadores e da relação da Escola com a sociedade.

As crianças serão enviadas para a Escola cada vez mais cedo e nela permanecerão por um tempo mais extenso. E isso não será porque há um mundo novo de informações a ser processado e, sim, porque a Escola deverá exercer o tradicional papel das famílias, das comunidades, da I greja, e ainda, o que lhe era próprio: desenvolver conhecimentos e habilidades. Ela deverá se ocupar com a formação integral do ser humano e terá como missão suprema a formação do sujeito ético.

Recebido para publicação em julho de 2001.

\section{N otas:}

1. Ver, por exemplo, a notável discussão que sobre estes termos podemos encontrar em Jaeger (1995), especialmente no livro primeiro, p. 130-147.

2. Faltaria tempo e espaço, nos limites deste texto, para um exame mais detal hado do movimento deste conceito nos autores mais representativos do pensamento moderno e contemporâneo. M as poderíamos indicar, preliminarmente, algumas pistas que podem ser encontradas, apenas nos tempos modernos, em pensadores como Spinoza, M ontaigne, Rousseau, $\mathrm{H}$ egel e especialmente, Kant, a quem retornaremos adiante.

3. Cf. A. Borón, 1966, p. 63.

4. Kant, 1993, p. 69.

5. Idem, Ibid., p. 73.

6. Creio ser importante justificar, nesse ponto, o uso que faço do termo "homem", ao longo deste texto. 0 leitor poderá notar que, ao falar de "homem", enquanto o sujeito da formação educa- 
cional, estou tomando esse termo no sentido de "ser humano"e não tratando do gênero masculino, cujo oposto seria a mulher.

7. M ontaigne, 1987, Livro 1, p. 219.

8. Esse tema eu desenvolvi no livro Elogio à educação, especialmente na segunda parte, intitulada "A educação do olhar".

9. M ontaigne, op. cit., p. 229. Essa concepção pode ser encontrada igualmente no projeto educativo desenvolvido por Rousseau no Emílio.

10. A inspiração para esta parte do texto veio da leitura de Verdade e método, de G adamer, conforme indicado nas referências bibliográficas. Em algumas partes do meu texto, utilizo idéias do autor referido de forma livre.

11. Gadamer, 1998, p. 643-645.

12. Idem, ibid., p. 645.

13. Ver especialmente Kant, Réflexions sur l'Éducation, e o texto "Resposta à pergunta: Q ue é o esclarecimento?". Para Kant, o sujeito chega ao comportamento Ético quando é capaz de agir orientado por princípios universais. Isso só é possível, pois, no estágio em que se chegou à maioridade, à autonomia. Logo, é etapa final do processo de sua formação. N a mesma direção, podemos igualmente examinar Adorno, em Educação e emancipação, especialmente a partir da p. 139, "Educação - para quê?".

\section{Education: From human training TO THE CONSTRUCTION OF ETHICAL SUBJECTS}

ABST RACT: T his text elaborates both a criticism and a proposal with regard to the educational issue. The critic denounces the consensual conception that ascribes the means and ends of Education, as a whole, to the current educational processes. It highlights that such a conception hangs together the pragmatic, utilitarian vision prevailing in both the political and social order of the world, and the role assigned to school education: preparing learners to exercisetheir citizen ship. It also explores - and denies - the close relationship between the attribute of citizen and individuals who take hold of knowledge and skills consi dered necessary to their integration as an efficient force within the productive sectors. This paper does not recognize access to knowledge and skills but as part of the human training process. As for its propositional aspect, it stresses the concept of Education as the integral process of human training, since every newborn human being needs to receive a new condition in order to exist in theworld of culture. Thisprocessincludestheacquisition of products that are part of the ci vilizing heritage and have contributed to exceeding thelimits of nature. Among them arerational knowledge, which promoted the scientific and cultural development of manhood, and the conscience that each human being isthe very producer of the reproducti on conditions of his own life and of the social forms of its organization. The latter must be oriented by the principles of solidarity, recognition of the value of individualities, respect to differences, and by the discipline of wills. The $H$ uman Being, once he does not receive any determination by nature, may construct his own way of life on the bases of F ree will, autonomy to 
organize his manners of living and responsibility for the direction of his actions. This human feature constitutes the foundation of the ethical subject training, which hasto be the essential objective of Education, and to which whatever educational practice, including those concerned with school, must be subjected. Finally, thetext addresses what the author believes to be the future of School. I nsofar as, in modern society, it is becoming the most legitimate space to carry out the education of children and teenagers, it will have to change in order to embrace this function that will fall on it as a social injunction: being not only a place for schooling, but also, and above all, one of human and ethical subject training.

Key words: Education and human training; Education and ethical subjects, Autonomy and education; Education and liberty; Education versus schooling.

\section{Referênciasbibliográficas}

AD O RN O , T.W. Educação e emanci pação. Trad. de Wolfgang Leo M aar. Rio de Janeiro: Paz \& Terra, 1995.

AREN DT, H annah. A condição humana. Trad. Roberto Raposo. $6^{\text {a }}$ ed. Rio de Janeiro: Forense, 1993.

ARIST ÓTELES. Ética a Nicômaco. Trad. De Leonel Vallandro e Gerd Borheim. São Paulo: Vitor Civita (Col. O s Pensadores, 1973).

BACHELARD, G. A formação do espírito científico. Rio de Janeiro: Contraponto, 1996.

BERLIN, Isaiah. Limites da utopia: C apítulos da H istória das idéias. Trad. de Valter L. Siqueia. São Paulo: Companhia das Letras, 1991.

BORÓN, A. "A sociedade civil depois do dilúvio neoliberal". In: SADER, Emir \& GentILI, Pablo (O rgs.), Pósneoliberalismo: As políticas sociais e o Estado. Rio de Janeiro: Paz \& Terra, 1995.

CAST ELLS, M anuel. "A sociedade em rede". Trad. de Roneide V. M ajer. In: A era da informação: Economia, sociedade e cultura, vol. 1, São Paulo: Paz \& Terra, 1999.

GAD AM ER, H ans-Georg. Verdade e método. Trad. de Flávio Paulo M eurer. 2a ed. Petrópolis: Vozes, 1998.

JAEGER, Werner Wilhelm. Paidéia: A formação do homem grego. Trad. Artur M. Parreira. 3a ed. São Paulo: M artins Fontes, 1994. 
KAN T, I . "R esposta à pergunta: Q ueé esclarecimento?". In: Textos Seletos, Petrópolis: Vozes, 1974.

Crítica da razão prática. Trad. de Afonso Bertagnoli, Rio de Janeiro, 1967 (Clássicos de Bolso).

Réflexions sur L'Éducation. Introduction, traduction et notes par Alexis Philonenko. Paris: Libraire Philosophique J. Vrin, 1993.

M ONTAIGN E, M. E. Ensaios. 3 vols. Trad. Sérgio M illet, $2^{\text {a }}$ ed. São Paulo: Editora da UnB/H ucitec, 1987-1988.

RODRIGUES, N eidson. Elogio à educação. São Paulo: Cortez, 1999.

RO U SSEAU, J.J. Emílio ou Da educação. São Paulo: Difel, 1973. 